\title{
Size effect at testing strength properties of concrete
}

\author{
Amanda Akram \\ Department of Structural Engineering; Faculty of Civil Engineering and Architecture; \\ Lublin University of Technology; 40 Nadbystrzycka St., 20-618 Lublin, Poland; \\ a.akram@pollub.pl (D) 0000-0001-5619-2927
}

\begin{abstract}
Various strength characteristics of concrete are considered as fracture parameters. The compressive strength of concrete is of paramount importance when designing concrete structures, whereas tensile strength of concrete is the basic property when estimating cracking resistance of a structure and analysing fracture processes in concrete. When testing the compressive strength of concrete, the results are dependent on the shape and dimensions of used specimens. Some findings reported in the literature suggest that size effect exists also when testing such fracture properties of concrete as tensile strength. Unfortunately this problem is much less recognized and described compared to size effect in compressive test results. In this paper, the experimental investigation is presented on how the length of cylindrical specimens influences the tensile splitting strength of concrete obtained by means of the Brazilian method. Additional variable parameters were: type of aggregate (natural gravel and crushed granite) and cement-water ratio $(\mathrm{C} / \mathrm{W}=1.8$ and $\mathrm{C} / \mathrm{W}=2.6)$. In conducted laboratory experiments a higher splitting tensile strength of concrete was noted for all specimens with nominal dimensions of $150 \times 150 \mathrm{~mm}$, compared to specimens $150 \times 300 \mathrm{~mm}$ in size, regardless of type of aggregate or cement-water ratio.
\end{abstract}

Keywords: concrete, size effect, tensile strength

\section{Introduction}

Concrete is a composite material which is produced by mixing cement, water, fine and coarse aggregates. Some additives, for example pozzolanas and superplasticizers can be added to improve the mechanical and physical properties of the concrete mixture as well as hardened concrete. The proportions of ingredients are calculated according to appropriate methods to obtain a required quality of hardened concrete, which is particularly important with regard to its compressive and tensile strength. When designing concrete structures, the compressive strength of concrete is of paramount importance, whereas when estimating cracking resistance of structure and analysing fracture processes the tensile strength of concrete is the basic 
property. The tensile strength of concrete is much lower than its compressive strength and in normal strength concretes it reaches about $10 \%$ of compressive strength. Therefore, concrete is rated among quasi-brittle materials.

The bulk of concrete is made up of fine and coarse aggregates which should be of proper granulation. The type of aggregate is also crucial. Both crushed and gravel aggregates can be used as a coarse aggregate in concrete production. The internal structure of hardened concrete causes that concrete is an heterogeneous material and therefore its properties, especially the compressive and tensile strength, should be tested experimentally. Tests should be performed at standard conditions and using standardized specimens according to the code [1]. Concrete compressive strength should be tested in uniaxial compression test on cylindrical or cubic specimens according to the procedure given in the code [2]. To determine the tensile strength of concrete, indirect methods are usually applied due to the difficulty of performing the direct tensile test. As the standard method, the Brazilian splitting tensile test is recommended in the code [3]. The splitting test can be performed using both cylindrical and cubic specimens. Specimens which are admitted for testing, the compressive strength and the splitting tensile strength of concrete are presented in Fig. 1.
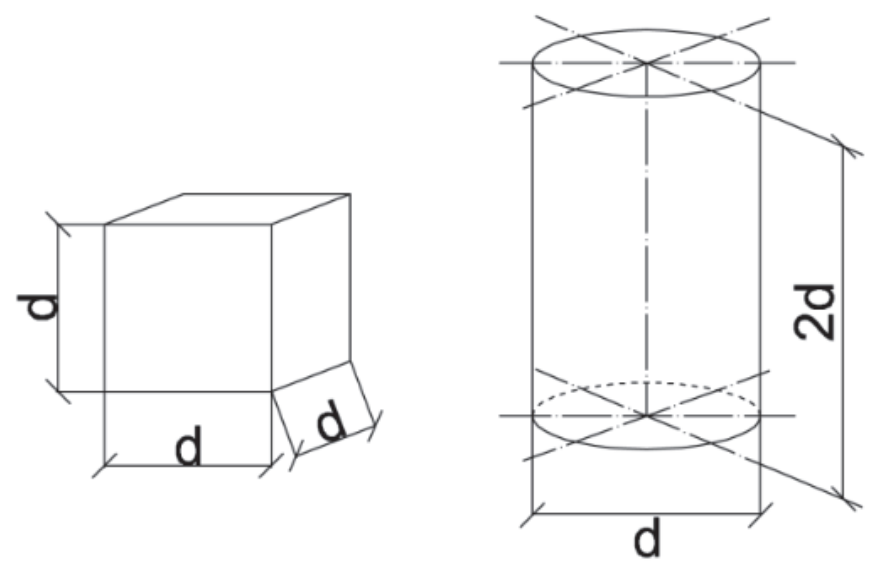

Fig. 1. Admissible types of specimens for testing concrete compressive and tensile strength. Nominal dimensions for cubes: $d=100,150,200,250,300 \mathrm{~mm}$, and for cylinders: $d=100,113,150,200$, $250,300 \mathrm{~mm}$, with acceptable dimension discrepancy $\pm 10 \%$

When testing the strength properties of concrete, the shape and dimensions of tested specimens are crucially important. The influence of a specimen's size on concrete compressive strength has been described in depth ([4]-[7]). The specimens which are the most often used in testing compressive strength of concrete are $150 \mathrm{~mm}, 100 \mathrm{~mm}$ and $200 \mathrm{~mm}$ cubes, and cylinders $150 \mathrm{~mm}$ in diameter and $300 \mathrm{~mm}$ long. The relations among concrete compressive strengths tested on different specimens are presented below (Eq. 1).

$$
f_{c, \text { cube } 15}=0.9 f_{c, \text { cube } 10}=1.05 f_{c, \text { cube } 20}=1.25 f_{c, c y l 15 / 30}
$$

where: $f_{\mathrm{c} \text {,cube } 15}$ - compressive strength tested on cubes $150 \mathrm{~mm}, f_{\mathrm{c} \text {,cube } 10}$ - compressive strength tested on cubes $100 \mathrm{~mm}, f_{\mathrm{c} \text {, cube } 20}$ - compressive strength tested on cubes $200 \mathrm{~mm} f_{\mathrm{c} \text {,cyl15/30- }}$ compressive strength tested on cylinders $150 \mathrm{~mm}$ in diameter and $300 \mathrm{~mm}$ in length. 
Some findings reported in the literature suggest that size effect also plays an important role when testing fracture properties of concrete such as tensile strength ([8]-[10])and fracture energy ([11]-[12]). Unfortunately, this problem is much less recognized and described. Furthermore, specimens of different shapes and dimensions are used when testing tensile strength of concrete. The schematic diagrams of examples of control specimens under loading for the measurement of tensile strength of concrete are shown in Fig. 2.
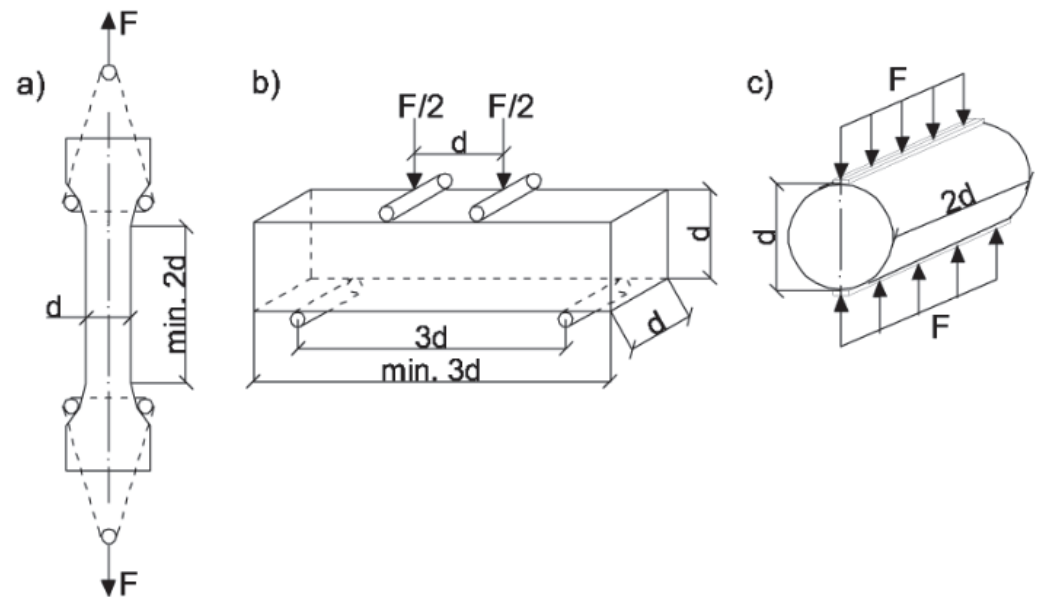

Fig. 2. Test methods of tensile strength of concrete (with examples of admissible control specimens): a) uniaxial tensile test, b) flexural test, c) split cylinder test

The uniaxial tensile test is conducted on rectangular prisms of a cross section $100 \times 100 \mathrm{~mm}$ or $150 \times 150 \mathrm{~mm}$ and the length equals two times the specimen's width. The specimen is fixed in the load frame of the testing machine by wider ends of the specimens. In case of cylindrical specimens (which are also acceptable) grip handles or stiff plates glued to the face of the specimens are used for fixing. In the uniaxial test, the maximum axial load is measured when the failure of the specimen appears in the middle part of the specimen's length and the tensile strength is calculated from Eq. 2.

$$
f_{c t, \operatorname{dir}}=\frac{F}{A}
$$

where: $F$-failure load, $A$ - cross section area in a damaged place. When performing the flexural tensile test two static schemes are possible: a three point bending test and a four point bending test. As a standard method a simple plain concrete beam loaded at one-third span point is recommended. The span of the beam should be three times its depth. The typical arrangement for the test is presented in Fig. 2b. The flexural tensile strength is computed as a maximum tensile stress from the standard flexural formulas: Eq. 3 in case of two point loading and Eq. 4 in case of one point loading.

$$
\begin{aligned}
& f_{c t, f l}=\frac{M}{W_{c}}=\frac{F \cdot l}{d_{1} \cdot d_{2}^{2}} \\
& f_{c t, f l}=\frac{M}{W_{c}}=\frac{3 \cdot F \cdot l}{2 \cdot d_{1} \cdot d_{2}^{2}}
\end{aligned}
$$

where: $F$ - failure load, $l$-span of the beam, $d_{1}$ and $d_{2}$ - dimensions of beam's cross section. 
It should be noted that a static scheme in flexural tensile test also influences the obtained results. Tensile strength is $13 \%$ higher when performing the test in three point bending compared to four point bending. Therefore, loading arrangement by two concentrated forces is recommended in the code [13].

During the splitting test, a specimen is placed in the compression testing machine (cylinders in a horizontal position) and the load is applied through plywood strips situated under and over the specimen in a central position. The specimen fails in tension into two halves (see Fig. 3). The concrete splitting tensile strength is calculated from Eq. 5.

$$
f_{c t, s p}=\frac{2 \cdot F}{\pi \cdot L \cdot d}
$$

where: $F$ - failure load, $L$ - specimen's length, $d$ - dimension of a specimen's cross section.
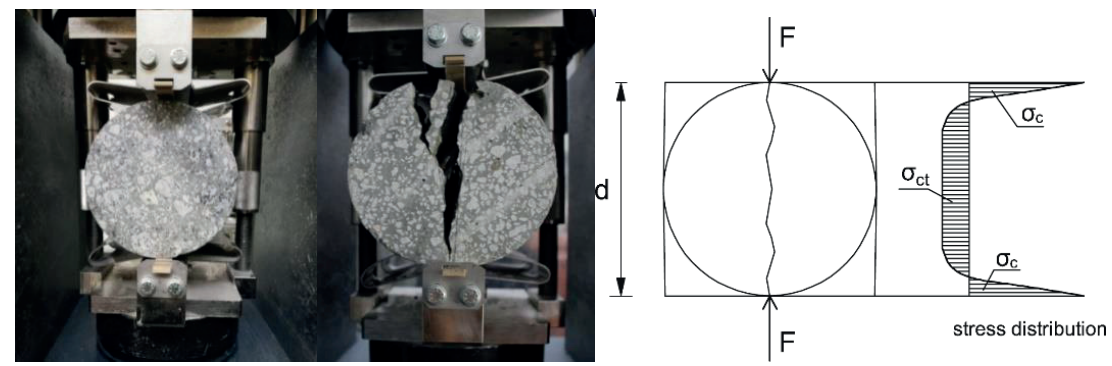

Fig. 3. The Brazilian splitting test: specimen in the test stand before and after the failure (left); stress distribution in cross section $\sigma_{\mathrm{ct}}-$ tensile stress, $\sigma_{\mathrm{c}}-$ compressive stress (right)

It can be suspected that the shape and size of specimens have a certain influence on tensile concrete strength tested in the Brazilian test. In the code [3] we can find only a short comment on the shape and dimensions of specimens used during the splitting tensile concrete strength saying that the tensile strength tested on cubic specimens is approximately $10 \%$ higher than on cylindrical specimens, and that the higher tensile strength is obtained using smaller cubic specimens. There is no information on how the size of cylindrical specimens influence the tensile splitting strength of concrete.

In the paper the experimental investigation is presented on how the size of cylindrical specimens influences the tensile splitting strength of concrete.

\section{Laboratory experiments}

Experiments were performed to evaluate the impact of a cylinder's length on tensile concrete strength received in the Brazilian method. Cylindrical specimens with a diameter of $150 \mathrm{~mm}$ and varied length equalling to $300 \mathrm{~mm}$ and $150 \mathrm{~mm}$ respectively were used. Additionally, four different concrete mixtures were designed for forming the specimens. The variable experiment parameters were: two types of aggregate (natural gravel and crushed granite) and two cement-water ratios $(\mathrm{C} / \mathrm{W}=1.8$ and $\mathrm{C} / \mathrm{W}=2.6)$. Each concrete mixture was based on the maximum aggregate size $16 \mathrm{~mm}$.

The laboratory tests were performed in two stages. The first one included a pilot study involving fewer test specimens. The second one comprised of more specimens. During both stages the same conditions concerning the aggregate type and a $\mathrm{C} / \mathrm{W}$ ratio were kept. 
On this account it was possible to gather more results in a larger testing group and to carry out a statistical analysis in a wider spectrum. In the size effect analysis concerning the tensile splitting tests, the results from both stages were taken into account together, due to identical recipes for concrete mixtures and the same types of aggregates.

The composition of the aggregate grading curve played a significant role in the concrete mixture design. The proportion of aggregate granulation was very similar in concrete mixtures with gravel and granite aggregates. A second key point was to fit the grading curves in the recommended area [14], between the upper and lower limit curves (Fig. 4 and Fig. 5).
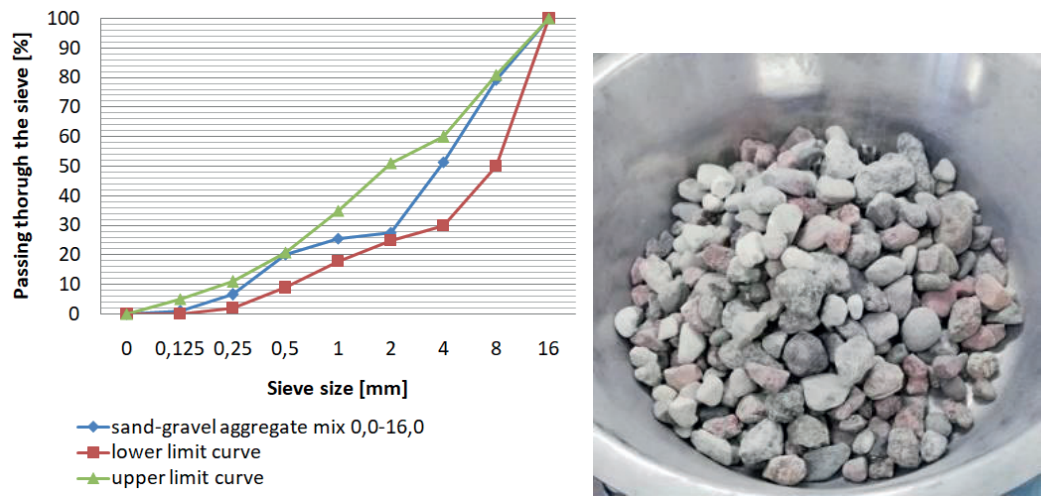

Fig. 4. Grading curve for sand and natural aggregate mixture (on the left); natural aggregate - fraction 8-16 (on the right)

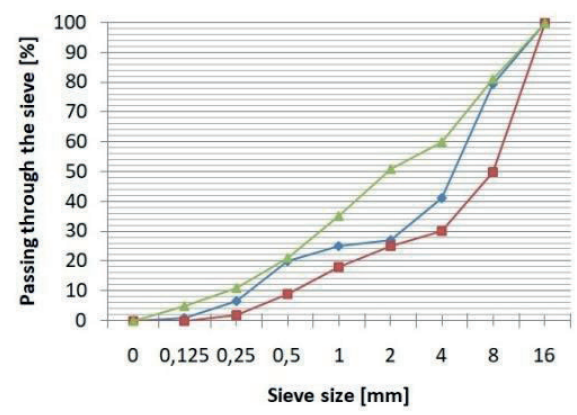

$\rightarrow$ sand-crushed aggregate mix 0,0-16,0

$\rightarrow-$ lower limit curve

- upper limit curve

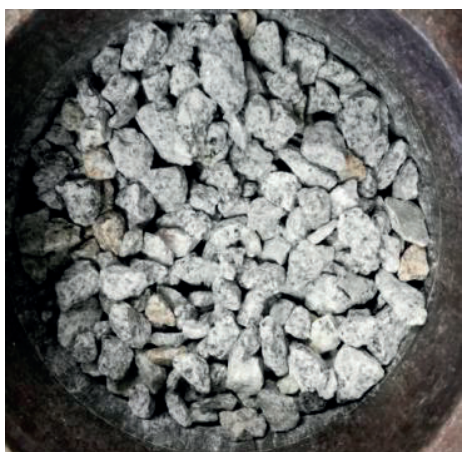

Fig. 5. Grading curve for sand and crushed aggregate mixture (on the left); crushed aggregate - fraction 8-16 (on the right)

Two types of aggregates were used for preparing various concretes: one with a lower strength matrix $(\mathrm{C} / \mathrm{W}=1.8)$ and the other with a higher strength matrix $(\mathrm{C} / \mathrm{W}=2.6)$. Apart from the aggregate granulation, the cement matrix is one of the fundamental elements of the heterogenic structure of hardened concrete which influences the fracture processes ([15]-[19]). Therefore, the cement matrix was considered as an important strength parameter during laboratory investigations and it was tested in the flexural strength test of hardened cement mortar. The 
tests were carried out in accordance with the code [20], on beams $40 \mathrm{~mm} \times 40 \mathrm{~mm} \times 160 \mathrm{~mm}$ in size, in a three-point bending test (Fig. 6). The proportions of water, cement and sand in the mortars were modified to obtain a proper consistency of the concrete mixtures comparing to requirements given the code PN-EN 196-1.

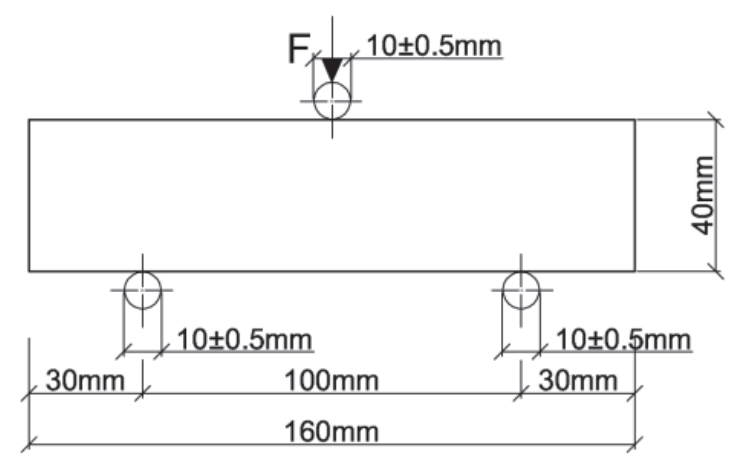

Fig. 6. A loading arrangement for testing flexural strength of cement mortar on a prism specimen according to PN-EN 196-1

Table 1. Composition of concrete mixtures

\begin{tabular}{lllllll}
\hline Aggregate type & $\mathrm{C} / \mathrm{W}$ & $\begin{array}{l}\text { Cement } \\
{\left[\mathrm{kg} / \mathrm{m}^{3}\right]}\end{array}$ & $\begin{array}{l}\text { Water } \\
{\left[\mathrm{kg} / \mathrm{m}^{3}\right]}\end{array}$ & $\begin{array}{l}\text { Sand0.0-2.0 } \\
{\left[\mathrm{kg} / \mathrm{m}^{3}\right]}\end{array}$ & $\begin{array}{l}\text { Coarse aggregate } \\
2.0-16.0\left[\mathrm{~kg} / \mathrm{m}^{3}\right]\end{array}$ \\
\hline 1 & Granite & 1.8 & 375.6 & 206.6 & 481.0 & 1300.5 \\
\hline 2 & Granite & 2.6 & 580.7 & 223.4 & 421.6 & 1140.0 \\
\hline 3 & Gravel & 1.8 & 349.8 & 192.4 & 497.1 & 1344.0 \\
\hline 4 & Gravel & 2.6 & 533.6 & 205.2 & 445.5 & 1204.5 \\
\hline
\end{tabular}

The compositions of concrete mixtures are shown in Table 1. The flexural strength of the weaker cement matrix $(\mathrm{C} / \mathrm{W}=1.8)$ was $6.80 \mathrm{MPa}$ and the flexural strength of the stronger matrix $(\mathrm{C} / \mathrm{W}=2.6)$ was $8.78 \mathrm{MPa}$.

Test results of tensile splitting strength are presented in Table 2.

Table 2. Test results

\begin{tabular}{|c|c|c|c|c|c|c|c|}
\hline & $\begin{array}{l}\text { Aggregate } \\
\text { type }\end{array}$ & $\mathrm{C} / \mathrm{W}$ & $\begin{array}{l}\text { Cylinder's } \\
\text { dimensions } \\
{[\mathrm{mm}]}\end{array}$ & $\begin{array}{l}\text { Tensile strength } \\
- \text { mean value } \\
{[\mathrm{MPa}]}\end{array}$ & $\begin{array}{l}\text { Number of } \\
\text { specimens } \\
{[-]}\end{array}$ & $\begin{array}{l}\text { Standard } \\
\text { deviation, } \sigma_{\mathrm{s}} \\
{[\mathrm{MPa}]}\end{array}$ & $\begin{array}{l}\text { Coefficient } \\
\text { of variation } \\
{[\%]}\end{array}$ \\
\hline \multirow{2}{*}{1} & \multirow{2}{*}{ Granite } & \multirow{2}{*}{1.8} & $150 \times 300$ & 3.40 & 8 & 0.123 & 3.6 \\
\hline & & & $150 \times 150$ & 3.49 & 8 & 0.295 & 8.5 \\
\hline \multirow{2}{*}{2} & \multirow{2}{*}{ Granite } & \multirow{2}{*}{2.6} & $150 \times 300$ & 3.78 & 8 & 0.415 & 11.0 \\
\hline & & & $150 \times 150$ & 4.22 & 8 & 0.332 & 7.9 \\
\hline \multirow{2}{*}{3} & \multirow{2}{*}{ Gravel } & \multirow{2}{*}{1.8} & $150 \times 300$ & 2.68 & 8 & 0.227 & 8.5 \\
\hline & & & $150 \times 150$ & 2.96 & 7 & 0.203 & 6.5 \\
\hline \multirow{2}{*}{4} & \multirow{2}{*}{ Gravel } & \multirow{2}{*}{2.6} & $150 \times 300$ & 3.54 & 8 & 0.197 & 5.6 \\
\hline & & & $150 \times 150$ & 3.77 & 8 & 0.259 & 6.9 \\
\hline
\end{tabular}


In the conducted laboratory experiments, a higher splitting tensile strength of concrete was noted for all specimens with nominal dimensions of $150 \times 150 \mathrm{~mm}$ compared to specimens $150 \times 300 \mathrm{~mm}$ in size. That tendency was observed in every series of tested cylinders, both for concrete containing natural gravel, and crushed granite. The increase of tensile strength was $6.6 \%$ for the gravel concrete with the ratio $\mathrm{C} / \mathrm{W}=2.6$ (stronger concrete) and $15.9 \%$ for the gravel concrete with the ratio $\mathrm{C} / \mathrm{W}=1.8$ (weaker concrete). In case of the granite concrete, the strength increase was $2.9 \%$ for the lower $\mathrm{C} / \mathrm{W}$ and $11.7 \%$ for the higher $\mathrm{C} / \mathrm{W}$. However, this unique trend cannot be deduced from the obtained test results.

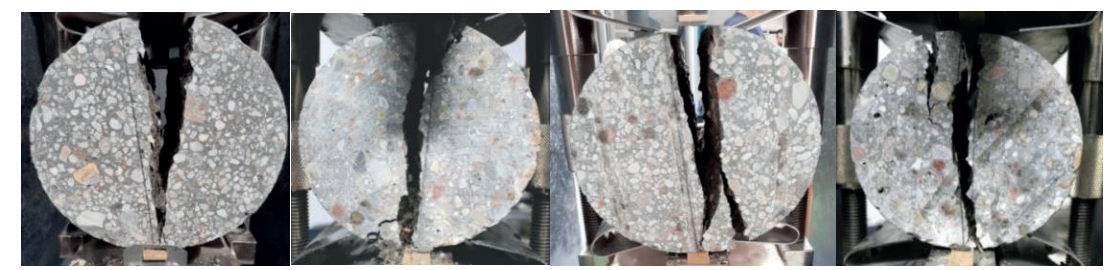

Fig. 7. Examples of the specimens' failure after the tensile splitting test, concrete with natural gravel aggregate (from the left): cylinder $150 \times 300, \mathrm{C} / \mathrm{W}=1.8$; cylinder $150 \times 150, \mathrm{C} / \mathrm{W}=1.8$; cylinder $150 \times 300$, $\mathrm{C} / \mathrm{W}=2.6$ and cylinder $150 \times 150, \mathrm{C} / \mathrm{W}=2.6$

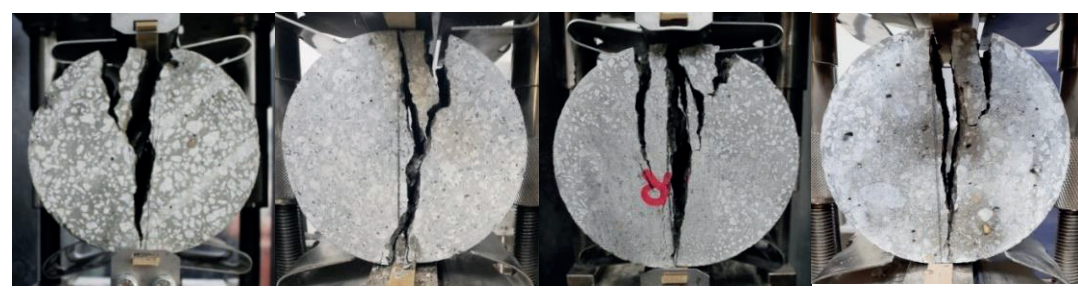

Fig. 8. Examples of the specimens' failure after the tensile splitting test, concrete with crushed granite aggregate (from the left): cylinder $150 \times 300, \mathrm{C} / \mathrm{W}=1.8$; cylinder $150 \times 150, \mathrm{C} / \mathrm{W}=1.8$; cylinder $150 \times 300, \mathrm{C} / \mathrm{W}=2.6$ and cylinder $150 \times 150, \mathrm{C} / \mathrm{W}=2.6$

The mode of failure for the tested specimens was similar and independent of aggregate type, cement water ratio $\mathrm{C} / \mathrm{W}$ and the specimen's length.

The failure of cylinders in the performed splitting tensile tests resulted from cracking in the plane of load application, usually together with wedges chipping off from the bulk concrete (Fig. 7 and 8). The more intensive destructive cracks observed at the points of contact of the specimen with the testing machine were caused by concrete crushing as a result of compressive stresses due to the stress distribution in failure cross section (as it is presented in Fig. 3).

\section{Conclusions}

The main conclusion from the performed experimental research is that the length of cylindrical specimens influences the tensile concrete strength when performing the Brazilian splitting test. Lower test results were obtained when using a longer cylindrical specimen $300 \mathrm{~mm}$ long compared with tensile strength on a shorter one $-150 \mathrm{~mm}$ long. However, due to a relatively big scatter of test results, it was not possible to draw conclusions about the 
quantitative relations between tensile splitting test derived on cylinders $300 \mathrm{~m}$ long and cylinders $150 \mathrm{~mm}$ long. The type of aggregate, gravel or crushed granite, or the flexural strength of cement matrix did not affect the test results.

The observed size effect at testing tensile splitting strength of concrete requires further research on more samples. When planning the experimental investigation it would be valuable to differ the aggregate granulation, in particularly the maximum aggregate size.

\section{References}

[1] EN 12390-1:2013-03 - Testing hardened concrete - Part 1: Shape, dimensions and other requirements for specimens and moulds, European Committee for Standardization, 2013.

[2] EN 12390-3:2019-07 - Testing hardened concrete - Part 3: Compressive strength of test specimen, European Committee for Standardization, 2019.

[3] EN 12390-6:2011 - Testing hardened concrete - Part 6: Tensile splitting strength of test specimen, European Committee for Standardization, 2011.

[4] Aitcin P.C., Miao B., Cook W., Mitchell D., "Effects of size and curing on cylinder compressive strength of normal and high-strength concretes", ACI Materials Journal, vol. 91(4), 1994, pp. 349-354.

[5] Malaikah A., "Effect of Specimen Size and Shape on the Compressive Strength of High Strength Concrete", Pertanika J Sci Technol, 13(1), 2005, pp. 81-96.

[6] Che Y. et al., "Effect of Specimen Shape and Size on Com-pressive Strength of Concrete", Advanced Materials Research, vol. 163-167, 2010, pp. 1375-1379. http://doi.org/10.4028/www.scientific. net/AMR.163-167.1375

[7] Sudin M.A.S., Ramli M., "Effect of Specimen Shape and Size on the Compressive Strength of Foamed Concrete", MATEC Web of Conferences, vol. 10(1), 2014. https://doi.org/10.1051/matecconf $/ 20141002003$

[8] Zhong W, Pan J, Wang J, Zhang C., "Size effect in dynamic splitting tensile strength of concrete: Experimental investigation", Construction and Building Materials, vol. 270(3), 2020. https://doi. org/10.1016/j.conbuildmat.2020.121449

[9] Liu J, Wenxuan Y, Xiuli D, Wangxian Y., "Mesoscopic numerical simulation of dynamic size effect on the splitting-tensile strength of concrete", Engineering Fracture Mechanics, vol. 209, 2019, pp. 317-332. https://doi.org/10.1016/j.engfracmech.2019.01.035

[10] Suchorzewski J, Tejchman J, Nitka M., "Experimental and numerical investigations of concrete behaviour at meso-level during quasi-static splitting tension", Theoretical and Applied Fracture Mechanics, vol. 96, 2018, pp. 720-739. https://doi.org/10.1016/j.tafmec.2017.10.011

[11] Zhu R., "Scale and Aggregate Size Effects on Concrete Fracture: Experimental Investigation and Discrete Element Modelling", Civil Engineering, Écolecentrale de Nantes, 2018.

[12] Chandran K. S.R., Galyon Dorman S., "The nature of specimen-size-effect on fatigue crack growth and net-section fracture mechanics approach to extract the size-independent behavior", International Journal of Fatigue, vol. 145(2), 2021. https://doi.org/10.1016/j.ijfatigue.2020.106088

[13] EN 12390-5:2019-08 - Testing hardened concrete: Flexural strength of test specimens, European Committee for Standardization, 2019.

[14] PN-B-06250-Beton zwykty (Eng. Plain concrete), Polski Komitet Normalizacyjny Miar i Jakości, 1988.

[15] Benkemoun N., Khazraji H.A., Poullain P., Choinska M., Khelidj A., "3-D mesoscale simulation of crack-permeability coupling in the Brazilian splitting test", International Journal for Numerical and Analytical Methods in Geomechanics, vol. 42(1), 2017, pp. 1-20. https://doi.org/10.1002/ nag. 2749 
[16] Słowik M., Stroeven P., Akram A., "Crack mechanisms in concrete - from micro to macro scale", Budownictwo i Architektura, 19(4), 2020, pp. 55-65. http://doi.org/10.35784/bud-arch.2147

[17] Karamloo M., Mazloom M., Payganeh G., "Influences of water to cement ratio on brittleness and fracture parameters of self-compacting lightweight concrete", Engineering Fracture Mechanics, 168(A), 2016, pp. 227-241. http://doi.org/10.1016\%2Fj.engfracmech.2016.09.011

[18] Nitka M., Tejchman J., "Meso-mechanical modelling of damage in concrete using discrete element method with porous ITZs of defined width around aggregates", Engineering Fracture Mechanics, 231, 2020, https://doi.org/10.1016/j.engfracmech.2020.107029.

[19] Sadrmomtazi A., Lotfi-Omran O., Nikbin I.M., "Influence of cement content and maximum aggregate size on the fracture parameters of magnetite concrete using WFM, SEM and BEM", Theoretical and Applied Fracture Mechanics, 107, 2020, https://doi.org/10.1016/j.tafmec.2020.102482.

[20] EN 196-1:2016-07 - Methods of testing cement - Part 1: Determination of strength, European Committee for Standardization, 2016. 
